\title{
Prognostic significance of histologic differentiation, carcinoembryonic antigen value, and lymphovascular invasion in stage I non-small cell lung cancer
}

\author{
Shuenn-Wen Kuo, MD, Jin-Shing Chen, MD, PhD, Pei-Ming Huang, MD, Hsao-Hsun Hsu, MD, PhD, \\ Hong-Shiee Lai, MD, PhD, and Jang-Ming Lee, MD, PhD
}

\begin{abstract}
Objective: For stage I non-small cell lung cancer (NSCLC), the only 2 prognostic factors incorporated into the seventh edition of the TNM staging system were tumor size and visceral pleural invasion. However, with this staging system, the prognostic precision of survival has proved elusive, suggesting the need to include additional prognostic factors. To improve prognostic applications and treatment decisions, we investigated clinicopathologic factors affecting progression-free survival in patients with surgically resected stage I NSCLC.
\end{abstract}

\begin{abstract}
Methods: From January 2004 to December 2011, we retrospectively reviewed the clinicopathologic characteristics of 758 consecutive patients with surgically resected stage I NSCLC at the National Taiwan University Hospital.
\end{abstract}

Results: The 5-year progression-free survival rate was $82.3 \%$ and $64.0 \%$ for those with stage IA $(n=481)$ and stage IB $(n=277)$, respectively. Multivariate analysis revealed poor or moderate histologic differentiation and elevated preoperative serum carcinoembryonic antigen were statistically significant risk factors for recurrence in patients with stage IA. Poor or moderate histologic differentiation, elevated preoperative serum carcinoembryonic antigen, lymphovascular invasion, and tumor size $>2 \mathrm{~cm}$ were statistically significant risk factors for recurrence in patients with stage I NSCLC. The 5-year progression-free survival rate was $93.0 \%, 73.8 \%$, and $40.6 \%$ for stage I patients with no, 1 or 2 , and $>2$ risk factors, respectively $(P<.001)$.

Conclusions: In addition to tumor size, we identified 3 other independent risk factors for recurrence in patients with stage I NSCLC. These 3 risk factors warrant consideration as additional predictors in the next version of the TNM staging system. (J Thorac Cardiovasc Surg 2014;148:1200-7)

Of Supplemental material is available online.

Lung cancer is one of the leading causes of cancer death worldwide. ${ }^{1}$ About $80 \%$ of lung cancers will be non-small cell lung cancer (NSCLC). ${ }^{2}$ The overall 5-year survival rate has remained poor at $14 \%$ to $17 \%$, and even those diagnosed with resectable stage I disease have had a 5-year survival rate of only $60 \%$ to $90 \%$, with a 5 -year recurrence rate

From the Division of Thoracic Surgery, Department of Surgery, National Taiwan University Hospital and National Taiwan University College of Medicine, Taipei, Taiwan.

The present study was supported by the National Health Research Institutes (grant NHRI-EX101-10032BI), Department of Health, Executive Yuan (grant DOH101-TD-PB-111-NSC003), and the National Science Council Taiwan (grant NSC101-2314-B002-020-MY3) of the Republic of China.

Disclosures: Authors have nothing to disclose with regard to commercial support.

Drs Kuo and Chen contributed equally to the present study.

Received for publication July 14, 2013; revisions received April 9, 2014; accepted for publication April 17, 2014; available ahead of print July 1, 2014.

Address for reprints: Jang-Ming Lee, MD, PhD, Division of Thoracic Surgery, Department of Surgery, National Taiwan University Hospital and National Taiwan University College of Medicine, No. 7, Chung-Shan South Rd, Taipei 10002,

Taiwan (E-mail: jmlee@ntu.edu.tw).

$0022-5223 / \$ 36.00$

Copyright (c) 2014 by The American Association for Thoracic Surgery

http://dx.doi.org/10.1016/j.jtcvs.2014.04.038 of $\sim 40 \% .^{3-6}$ Thus, considerable prognostic variation remains for patients with stage I NSCLC. Surgical resection has been the treatment of choice for stage I lung cancer. In our experience, however, a small minority of stage I patients will experience early recurrence after tumor resection.

With improvements in computed tomography (CT) imaging leading to greater resolution and the increased prevalence of CT screening for lung cancer detection in asymptomatic patients, early lung cancers have been more frequently than previously. ${ }^{7}$ The current standard for performing NSCLC pathologic TNM staging is based on guidelines from the American Joint Committee on Cancer (AJCC) Cancer Staging Manual, seventh editon. ${ }^{8}$ For stage I NSCLC, the only 2 prognostic factors incorporated into the current TNM staging system were large tumor size and visceral pleural invasion. Noting that the current staging system has led to excessively imprecise prognostic estimation of survival and difficulties in successfully determining when adjuvant therapy would be indicated, several studies have focused on investigating these and various other potential prognostic factors for early lung cancer. However, the staging system has remained unchanged. ${ }^{5,6,9-16}$ In an additional effort to help reach a consensus on how to improve prognostic precision 


\section{Abbreviations and Acronyms \\ AJCC = American Joint Committee on Cancer \\ CEA $=$ carcinoembryonic antigen \\ $\mathrm{CT}=$ computed tomography \\ NSCLC $=$ non-small cell lung cancer \\ PET = positron emission tomography}

and treatment decisions, our study investigated the clinicopathologic factors affecting progression-free survival in our comparatively large sample of 758 patients who had been diagnosed with stage I NSCLC and had undergone surgical resection.

\section{METHODS}

\section{Patients}

From January 2004 to December 2011, we retrospectively reviewed 1571 consecutive patients with surgically resected NSCLC at the National Taiwan University Hospital. Of these patients, 850 had been diagnosed with pathologic stage I according to the "AJCC TNM Classification for Lung and Pleural Tumors" (seventh edition). ${ }^{8}$ Of these, 92 patients had received neoadjuvant therapy (chemotherapy and/or radiotherapy) or had presented with synchronous primary lung tumors and were excluded. The remaining 758 patients, including 481 with stage IA and 277 with stage IB, were enrolled in the present study. The National Taiwan University Hospital research ethics committee approved the study.

The preoperative staging procedure incorporated chest radiography; blood chemistry analysis and serum carcinoembryonic antigen (CEA) measurement; CT of the chest, abdomen, and brain; bone scanning or positron emission tomography (PET); and pulmonary function tests. All patients had undergone systematic lymph node dissection. Sublobar resections, including wedge resection and segmentectomy, were performed in patients with compromised pulmonary reserve or pure or mixed ground glass lesions $\leq 2.0 \mathrm{~cm}$ in size. In these patients, systematic lymph node dissection was still performed, including the mediastinal lymph nodes and interlobar lymph nodes. In addition, the surgical margin of the wedge resection was $>2 \mathrm{~cm}$. The clinicopathologic parameters, including age, gender, smoking status, preoperative serum CEA level, underlying malignant disease, lung cancer family history, surgical procedure (wedge resection, segmentectomy, lobectomy, or bilobectomy), surgical approach (thoracotomy or video-assisted thoracoscopic surgery), and mortality, were collected from a review of the medical records and by telephone interview.

All specimens were fixed using formalin and sectioned for microscopic examination with hematoxylin and eosin staining. Histopathologic studies were done in accordance with the World Health Organization criteria. ${ }^{17}$ The histologic diagnosis and pathologic features were documented from the pathologic analysis at National Taiwan University Hospital, including tumor cell type, tumor size, histologic differentiation, visceral pleural invasion, and lymphovascular invasion. The tumor size was defined as the greatest dimension. The histologic differentiation grade was categorized as well-, moderately, and poorly differentiated carcinoma. Visceral pleural invasion was defined as present when the tumor had invaded beyond the elastic layer of the visceral pleura but had not invaded the parietal pleura. Lymphovascular invasion was defined as either the presence of vascular invasion or lymphatic permeation.

\section{Patient Follow-up}

The patients were regularly monitored for the first 2 years in the outpatient clinic with physical examination, chest radiography, serum CEA measurement 4 times annually, and chest CT 2 times annually. Thereafter, the patients were regularly monitored in the outpatient clinic with physical examination, chest radiography, serum CEA measurement, and chest CT every 6 months or annually according to the attending physician's instructions.

Brain CT, magnetic resonance imaging, bone scanning, PET, and other necessary tests were performed whenever any symptoms or signs of tumor recurrence were noted. Nodal failure was defined as the presence of an enlarged lymph node $(\geq 1 \mathrm{~cm})$ located on the short axis identified by chest $\mathrm{CT}$ or a hypermetabolic condition identified by PET. The diagnosis of recurrence was further confirmed cytologically or histologically by thoracocentesis of malignant pleural effusion, needle biopsy, or surgery, when clinically feasible. In accordance with the recommendations from the American College of Chest Physicians, ${ }^{18}$ a second distinct occurrence of primary lung cancer, rather than a first distant recurrence, was diagnosed if either one of the following criteria was present: (1) the histologic type was different; or (2) the histologic type was the same, the postoperative interval was $\geq 2$ years, and neither systemic nor N2/N3 lymph node metastasis was identified.

\section{Statistical Analysis}

The data were analyzed using the Statistical Package for Social Sciences, version 15 (SPSS, Inc, Chicago, Ill). The clinical characteristics, histologic findings, surgical procedures, approach methods, and patient outcomes were recorded. Categorical variables such as gender and smoking status are presented as frequencies and percentages and were analyzed using the Fisher exact test. The freedom from recurrence period was calculated from the date of surgery to the date of the first recurrence or last follow-up examination. Patients who had died of another disease or were progression free at the last follow-up visit were censored to calculate the progression-free survival rates. For univariate analysis, progression-free survival was calculated using Kaplan-Meier survival plots, and comparisons were made using the log-rank test. The variables achieving statistical significance on univariate analysis were included in the multivariate analysis using a Cox proportional hazard regression model. All tests were 2 -sided.

\section{RESULTS \\ Patient Demographics and Clinicopathologic Characteristics}

The study included 481 patients with stage IA and 277 with stage IB NSCLC, with a mean follow-up period of 44.6 months. The median age at surgery was 62 years (range, 20-91). The preoperative serum CEA values were abnormal in 76 patients $(10.0 \%)$. Of the 758 patients, 121 $(16.0 \%)$ had been diagnosed with NSCLC plus other primary malignancies. The most frequently observed combined malignancies were breast cancer $(\mathrm{n}=22)$, colorectal cancer $(\mathrm{n}=21)$, and hepatocellular carcinoma $(\mathrm{n}=15)$. Other demographic data and clinicopathologic characteristics of the total study group of 758 patients with stage I NSCLC and stratified by stage (481 with stage IA and 277 with stage IB) are listed in Table 1.

Recurrences were noted in 142 patients, including 30 locoregional recurrences and 112 distant recurrences, and were diagnosed by biopsy (thoracocentesis of malignant pleural effusion, needle biopsy, or surgical biopsy) in $59.2 \%$, PET in $16.2 \%$, CT in $15.5 \%$, magnetic resonance imaging in $5.6 \%$, and bone scanning in $3.5 \%$. Of the 
TABLE 1. Patient clinicopathologic characteristics

\begin{tabular}{|c|c|c|c|}
\hline Characteristic & All patients & Stage IA & Stage IB \\
\hline Patients & 758 & 481 & 277 \\
\hline Age $(y)$ & $62(20-91)$ & $60(27-88)$ & $65(20-91)$ \\
\hline Male gender & $354(46.7)$ & $208(43.2)$ & $146(52.7)$ \\
\hline \multicolumn{4}{|l|}{ Smoking } \\
\hline No & $378(49.9)$ & $255(53.0)$ & $123(44.4)$ \\
\hline Yes & $165(21.8)$ & $93(19.3)$ & $72(26.0)$ \\
\hline NA & $215(28.4)$ & $133(27.7)$ & $82(29.6)$ \\
\hline \multicolumn{4}{|l|}{ CEA } \\
\hline Normal & 657 (86.7) & $435(90.4)$ & $222(80.1)$ \\
\hline Abnormal & $76(10.0)$ & $32(6.7)$ & 44 (15.9) \\
\hline NA & $25(3.3)$ & $14(2.9)$ & $11(4.0)$ \\
\hline Other malignancy & $121(16.0)$ & $81(16.8)$ & $40(14.4)$ \\
\hline Lung cancer family history & $46(6.1)$ & $33(6.9)$ & $13(4.7)$ \\
\hline \multicolumn{4}{|l|}{ Histologic type } \\
\hline Adenocarcinoma & $541(71.4)$ & $343(71.3)$ & 198 (71.5) \\
\hline $\begin{array}{l}\text { Bronchioloalveolar } \\
\text { carcinoma }\end{array}$ & $93(12.3)$ & $85(17.7)$ & $8(2.9)$ \\
\hline Squamous cell carcinoma & $83(10.9)$ & $34(7.1)$ & $49(17.7)$ \\
\hline Other & $41(5.4)$ & $19(4.0)$ & $22(7.9)$ \\
\hline \multicolumn{4}{|l|}{ Tumor size $(\mathrm{cm})$} \\
\hline$\leq 1$ & $137(18.1)$ & $135(28.1)$ & $2(0.7)$ \\
\hline $1-2$ & $215(28.4)$ & $189(39.3)$ & $26(9.4)$ \\
\hline $2-3$ & $214(28.2)$ & $157(32.6)$ & $57(20.6)$ \\
\hline $3-4$ & $130(17.2)$ & $0(0.0)$ & $130(46.9)$ \\
\hline $4-5$ & $62(8.2)$ & $0(0.0)$ & $62(22.4)$ \\
\hline \multicolumn{4}{|l|}{ Tumor site } \\
\hline LUL & $185(24.4)$ & $115(23.9)$ & $70(25.3)$ \\
\hline LLL & $116(15.3)$ & $73(15.2)$ & $43(15.5)$ \\
\hline RUL & $248(32.7)$ & $168(34.9)$ & $80(28.9)$ \\
\hline RML & $69(9.1)$ & $43(8.9)$ & $26(9.4)$ \\
\hline RLL & $140(18.5)$ & $82(17.0)$ & $58(20.9)$ \\
\hline \multicolumn{4}{|l|}{ Histologic differentiation } \\
\hline Well & $306(40.4)$ & $250(52.0)$ & $56(20.2)$ \\
\hline Moderately or poorly & $350(46.2)$ & 168 (34.9) & $182(65.7)$ \\
\hline NA & $102(13.5)$ & $63(13.1)$ & $39(14.1)$ \\
\hline Visceral pleural invasion & $123(16.2)$ & $0(0.0)$ & $123(44.4)$ \\
\hline Lymphovascular invasion & $102(13.5)$ & $36(7.5)$ & $66(23.8)$ \\
\hline \multicolumn{4}{|l|}{ Surgical procedure } \\
\hline Wedge or segmentectomy & $114(15.0)$ & $101(21.0)$ & $13(4.7)$ \\
\hline Lobectomy or bilobectomy & $644(85.0)$ & $380(79.0)$ & $264(95.3)$ \\
\hline \multicolumn{4}{|l|}{ Approach } \\
\hline Thoracotomy & 109 (14.4) & $41(8.5)$ & $68(24.5)$ \\
\hline VATS & 649 (85.6) & $440(91.5)$ & $209(75.5)$ \\
\hline Recurrence & $142(18.7)$ & $59(12.3)$ & $83(30.0)$ \\
\hline Mortality & $81(10.7)$ & $31(6.4)$ & $50(18.1)$ \\
\hline
\end{tabular}

Data presented as $\mathrm{n}(\%)$ or median (range). NA, Not available; CEA, carcinoembryonic antigen; $L U L$, left upper lobe; $L L L$, left lower lobe; $R U L$, right upper lobe; $R M L$, right middle lobe; $R L L$, right lower lobe; VATS, video-assisted thoracoscopic surgery.

patients with distant recurrence, $31(27.7 \%)$ had $>1$ recurrence at diagnosis. The common recurrent sites were the lung $(\mathrm{n}=68)$, bone $(\mathrm{n}=31)$, and brain $(\mathrm{n}=17$; Table E1). The 5-year overall survival rate was $92.0 \%$ for those with stage IA and $76.3 \%$ for those with stage IB (Figure 1, A). The 5-year progression-free survival rate was $82.3 \%$ for those with stage IA and $64.0 \%$ for those with stage IB (Figure 1, B).

\section{Recurrence-Free Probability and Clinicopathologic Characteristics: Stage IA $(n=481)$}

Univariate analysis identified 9 significant risk factors for recurrence: age $>65$ years, male gender, positive smoking status, elevated preoperative serum CEA, squamous cell carcinoma histologic type, poor or moderate histologic differentiation, thoracotomy approach, tumor size $>2 \mathrm{~cm}$, and lymphovascular invasion (Table E2). Multivariate analysis using the Cox proportional hazard regression model (Table 2) identified elevated preoperative serum CEA and poor or moderate histologic differentiation as the 2 statistically significant independent risk factors for recurrence among the patients with stage IA (Figure 2).

\section{Recurrence-Free Probability and Clinicopathologic Characteristics: Stage I $(n=758)$}

Univariate analysis identified 10 significant risk factors for recurrence: age $>65$ years, male gender, positive smoking status, elevated preoperative serum CEA, squamous cell carcinoma histologic type, poor or moderate histologic differentiation, thoracotomy approach, tumor size $>2 \mathrm{~cm}$, visceral pleural invasion, and lymphovascular invasion (Table E3). Multivariate analysis using the Cox proportional hazard regression model identified the 4 variables as statistically significant independent risk factors for recurrence in all 758 patients with stage I NSCLC (Table 3 and Figure 2): poor or moderate histologic differentiation, elevated preoperative serum CEA, lymphovascular invasion, and tumor size $>2 \mathrm{~cm}$.

\section{Recurrence-Free Probability for Patients With Stage I NSCLC and Risk Factors}

To assess the cumulative effect of the 4 risk factors identified on multivariate analysis (histological differentiation, CEA, lymphovascular invasion, and tumor size), the patients were divided according to the number of risk factors present. The 5-year progression-free survival rate of patients with stage I with no $(\mathrm{n}=240), 1(\mathrm{n}=204), 2(\mathrm{n}=225), 3$ $(\mathrm{n}=76)$, and $4(\mathrm{n}=13)$ risk factors was $93.0 \%, 78.9 \%$, $68.9 \%, 42.9 \%$, and $30.8 \%$, respectively (Figure 1,C). These rates suggested a different separation into 3 subgroups: no, 1 or 2 , and 3 or 4 risk factors. The 5-year progression-free survival rate was $93.0 \%, 73.8 \%$, and $40.6 \%$ for patients with stage I NSCLC with no $(\mathrm{n}=240)$, 1 or $2(n=429)$, and $>2(n=89)$ risk factors, respectively. The difference in the recurrence rate for these 3 subgroups was statistically significant $(P<.001$; Figure $1, D)$.

\section{DISCUSSION}

With the increased use of chest CT, small-size lung cancers can be found more frequently now than previously, 

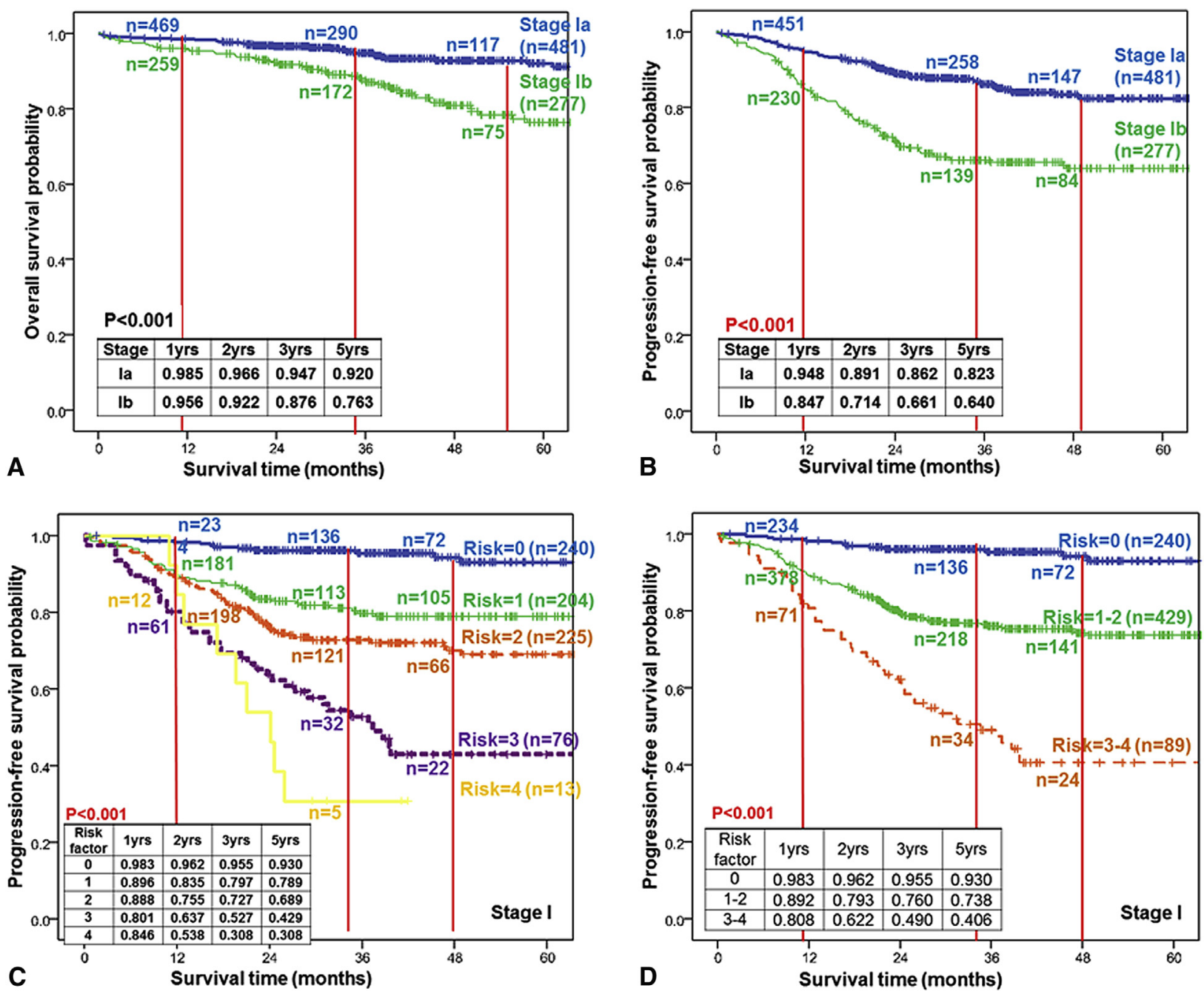

FIGURE 1. A, Overall survival of patients with different stages. B, Progression-free survival of patients with different stages. C and D, Patients with stage I disease and different numbers of risk factors. The 4 risk factors included histologic differentiation, preoperative serum carcinoembryonic antigen value, lymphovascular invasion, and tumor size $>2 \mathrm{~cm}$.

making management of early lung cancer an increasingly important issue. ${ }^{7}$ Using the current seventh AJCC TNM staging system, ${ }^{8}$ stage I NSCLC can be further classified into stage IA and IB, mainly according to whether the tumor size is $>3 \mathrm{~cm}$ and visceral pleural invasion is evident. However, several studies have reported many other prognostic factors in patients with early-stage NSCLC, including histologic differentiation, preoperative serum CEA value, PET standard uptake value, lymphovascular invasion, histologic type, surgical procedure, and surgical approach., ${ }^{5,6,9-16}$ In the present study, with one of the largest cohorts of patients with surgically resected stage I NSCLC, we analyzed all these prognostic factors and found that histologic differentiation and CEA were the 2 statistically significant independent risk factors for recurrence among patients with stage IA NSCLC. Also, histologic differentiation, CEA, lymphovascular invasion, and tumor size were independent risk factors for recurrence among patients with stage I as a whole.

Although the multivariate analysis revealed no statistically significant correlation between lymphovascular invasion and tumor size $>2 \mathrm{~cm}$ and poor progression-free survival in the stage IA group, the results still showed trends indicating a greater recurrence rate with lymphovascular invasion (hazard ratio, 1.78) and tumor size $>2 \mathrm{~cm}$ (hazard ratio, 1.57). The lack of the prognostic significance for these 2 factors in the stage IA group might have been related to the smaller number of patients.

Histologic differentiation has been reported as an independent risk factor for recurrence in NSCLC and other malignancies $5,9,10,19$ and was incorporated into the current esophageal pathologic seventh AJCC staging system in $2010 .^{19}$ Progression-free survival for patients with stage I NSCLC has been found to be significantly better for those 
TABLE 2. Progression-free survival multivariate analysis for patients with stage IA $(n=481)$

\begin{tabular}{|c|c|c|}
\hline Variable & Adjusted HR (95\% CI) & $P$ value \\
\hline Age (y) & & 291 \\
\hline$\leq 65$ & 1 & \\
\hline$>65$ & $1.31(0.79-2.18)$ & \\
\hline Gender & & .229 \\
\hline Female & 1 & \\
\hline Male & $1.39(0.81-2.36)$ & \\
\hline Smoking & & .731 \\
\hline No & 1 & \\
\hline Yes & $0.88(0.44-1.79)$ & \\
\hline CEA & & $.047 *$ \\
\hline Normal & 1 & \\
\hline Abnormal & $1.95(1.01-3.76)$ & \\
\hline \multicolumn{3}{|l|}{ Histological type } \\
\hline Adenocarcinoma & 1 & \\
\hline Bronchioloalveolar carcinoma & $0.47(0.13-1.73)$ & .257 \\
\hline Squamous cell carcinoma & $1.27(0.61-2.65)$ & .523 \\
\hline Others & $0.51(0.12-2.28)$ & .378 \\
\hline Histologic differentiation & & $.001 *$ \\
\hline Well & 1 & \\
\hline Moderately or poorly & $2.87(1.51-5.46)$ & \\
\hline Approach & & .108 \\
\hline VATS & 1 & \\
\hline Thoracotomy & $1.77(0.88-3.56)$ & \\
\hline \multicolumn{3}{|l|}{ Tumor size $(\mathrm{cm})$} \\
\hline$\leq 1$ & 1 & \\
\hline $1-2$ & $1.16(0.48-2.79)$ & .738 \\
\hline $2-3$ & $1.57(0.66-3.74)$ & .309 \\
\hline Lymphovascular invasion & & .079 \\
\hline Negative & 1 & \\
\hline Positive & $1.78(0.94-3.39)$ & \\
\hline
\end{tabular}

HR, Hazard ratio; $C I$, confidence interval; $C E A$, carcinoembryonic antigen; VATS, video-assisted thoracoscopic surgery. *Statistically significant.

diagnosed with well-differentiated carcinoma than for those with poorly or moderately differentiated carcinoma (5-year survival, $94.1 \%$ to $95.1 \%$ vs $77.8 \%$ to $78.5 \%$; 10 -year survival, $90.1 \%$ vs $67.8 \%$ to $76.8 \%$ ). ${ }^{5,9,10}$ These findings suggest that the biologic aggressiveness of the cancer cells could be related to the degree of differentiation and, thus, to cancer recurrence. In the present study, the 5-year progression-free survival rate was $90.2 \%$ for patients with well-differentiated carcinoma and $62.8 \%$ for those with poorly or moderately differentiated carcinoma. Lymphovascular invasion has also been identified as an independent risk factor for recurrence in early-stage lung cancer., ${ }^{5,9-11}$ The 5-year survival rate of patients with and without lymphovascular invasion was $74 \%$ and $93 \%$, respectively. ${ }^{11}$ Our study also showed that lymphovascular invasion was a statistically significant independent risk factor for recurrence. Our investigation found that both histopathologic prognostic factors considered (ie, histologic differentiation and lymphovascular invasion) were essential in determining the recurrence risk of stage I NSCLC.
CEA is a tumor marker in several malignancies, including NSCLC. The serum CEA value was elevated in about $40 \%$ to $60 \%$ of patients with advanced NSCLC and in only about $10 \%$ of those with early-stage NSCLC. ${ }^{12}$ Measuring the serum CEA value is a useful tool for monitoring the response to chemotherapy and recurrence in patients with advanced NSCLC. ${ }^{13}$ In the past 10 years, several studies have reported a poor prognosis for patients with high preoperative serum CEA values. ${ }^{12-16}$ Sawabata and colleagues ${ }^{14}$ reported a $49 \%$ 5-year survival rate for patients with stage I NSCLC and high preoperative serum CEA values compared with $72 \%$ for those with normal serum CEA values. Our study also showed a statistically significant difference in progression-free survival between patients with normal and high preoperative CEA values (5-year progression-free survival, $79.2 \%$ vs $49.3 \%$ ), further supporting the evidence that the preoperative serum CEA value is a useful predictor for recurrence in patients with stage I NSCLC.

Although the significant survival benefit of adjuvant chemotherapy has been shown in patients with stage II NSCLC, adjuvant chemotherapy for patients with stage I NSCLC has remained controversial. ${ }^{20,21}$ Our study revealed a discrepancy in the comparative progressionfree survival among the subgroups of stage I NSCLC. The progression-free survival was $75.7 \%$ in the total group of patients with stage I NSCLC. However, when we divided these patients into 3 subgroups according to the number of risk factors present, the 5-year progression-free survival rates were quite different: $93.0 \%, 73.8 \%$, and $40.6 \%$ for patients with no $(n=240), 1$ or $2(n=429)$, and $>2(n=89)$ risk factors, respectively. The subgroup of patients with $>2$ risk factors had a high recurrence risk, with a mere $40.6 \%$ 5-year progression-free survival, a level of risk similar to that typically found for patients with stage II or III NSCLC. Therefore, adjuvant chemotherapy might be considered for patients in this high-risk group.

We acknowledge that our study had limitations and biases. As a retrospective, single-institute study, patientselection and time-trend biases were inevitable. Most of our patients received a similar preoperative evaluation, postoperative care, and follow-up examinations during the 8-year study period (2004-2011). Compared with other retrospective studies, our relatively short study period should have helped to minimize the time-trend bias. However, prospective multi-institutional studies are still required to further validate the prognostic risk factors for recurrence of resected early-stage NSCLC. The current World Health Organization criteria ${ }^{17}$ have provided only a brief description of histologic grading for adenocarcinoma and squamous cell carcinoma. Therefore, variations in the assessment could exist among different pathologists. More clearly-defined criteria for grading differentiation 

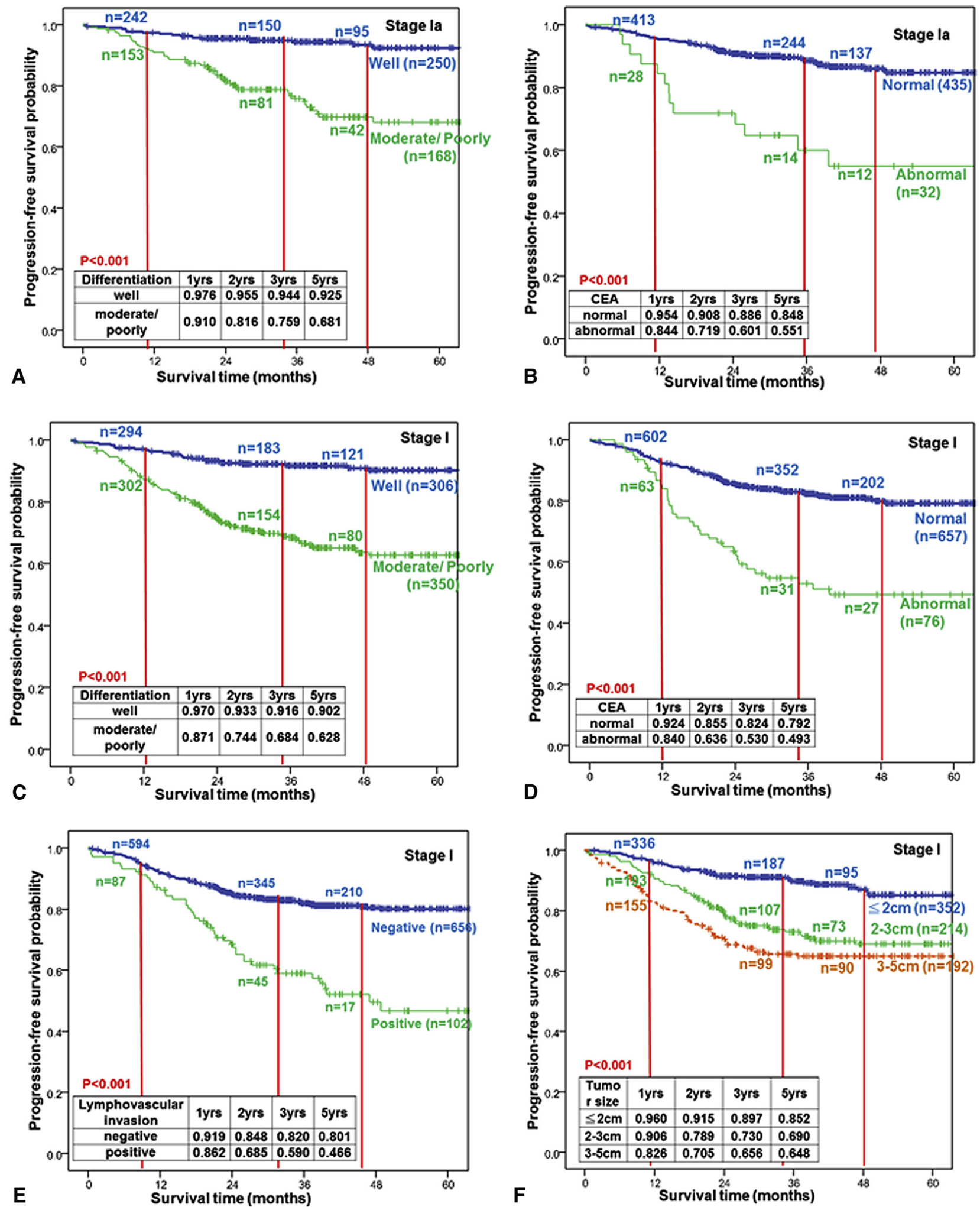

FIGURE 2. Progression-free survival of patients with stage IA stratified by (A) histologic differentiation and (B) preoperative serum carcinoembryonic antigen (CEA) value. Progression-free survival of patients with stage I stratified by (C) histologic differentiation, (D) preoperative serum CEA value, (E) lymphovascular invasion, and (F) tumor size. 
TABLE 3. Progression-free survival multivariate analysis for patients with stage $I(n=758)$

\begin{tabular}{|c|c|c|}
\hline Variable & Adjusted HR (95\% CI) & $P$ value \\
\hline Age (y) & & .785 \\
\hline$\leq 65$ & 1 & \\
\hline$>65$ & $1.05(0.76-1.44)$ & \\
\hline Gender & & .621 \\
\hline Female & 1 & \\
\hline Male & $1.09(0.77-1.55)$ & \\
\hline Smoking & & .940 \\
\hline No & 1 & \\
\hline Yes & $1.02(0.65-1.60)$ & \\
\hline CEA & & $.001^{*}$ \\
\hline Normal & 1 & \\
\hline Abnormal & $2.01(1.36-2.98)$ & \\
\hline \multicolumn{3}{|l|}{ Histological type } \\
\hline Adenocarcinoma & 1 & \\
\hline Bronchioloalveolar carcinoma & $0.38(0.13-1.09)$ & .072 \\
\hline Squamous cell carcinoma & $1.21(0.77-1.90)$ & .399 \\
\hline Others & $0.64(0.28-1.46)$ & .290 \\
\hline Histologic differentiation & & $.001^{*}$ \\
\hline Well & 1 & \\
\hline Moderately or poorly & $2.29(1.44-3.66)$ & \\
\hline Approach & & .250 \\
\hline VATS & 1 & \\
\hline Thoracotomy & $1.26(0.85-0.1 .88)$ & \\
\hline \multicolumn{3}{|l|}{ Tumor size $(\mathrm{cm})$} \\
\hline$\leq 2$ & 1 & \\
\hline $2-3$ & $1.54(1.01-2.35)$ & $.047 *$ \\
\hline $3-5$ & $1.69(1.09-2.62)$ & $.018^{*}$ \\
\hline Visceral pleural invasion & & .427 \\
\hline Negative & 1 & \\
\hline Positive & $1.16(0.80-1.69)$ & \\
\hline Lymphovascular invasion & & $.002 *$ \\
\hline Negative & 1 & \\
\hline Positive & $1.81(1.25-2.61)$ & \\
\hline
\end{tabular}

HR, Hazard ratio; $C I$, confidence interval; CEA, carcinoembryonic antigen; VATS, video-assisted thoracoscopic surgery. *Statistically significant.

might be necessary to achieve reproducible assessments. Despite these limitations, we have clearly identified 3 recurrence risk factors not included in the seventh AJCC TNM staging system for stage I NSCLC. In 2010, Maeda and colleagues, ${ }^{10}$ in a study of 713 patients with stage I tumors $\leq 3$ $\mathrm{cm}$, also found histologic differentiation, vessel invasion, and visceral pleural invasion were 3 independent risk factors for recurrence. Koo and colleagues, ${ }^{16}$ in 2011, in a study of 310 patients with stage I or II NSCLC also concluded that the preoperative CEA level, adenocarcinoma histologic type, and standard uptake value of the PET images were prognostic factors for recurrence. Our study identified the same prognostic factors but did so with a shorter study period within the past decade, adding support to the claim that these factors are significant and could be potentially used to further refine the next version of the AJCC TNM staging system and could also help to determine candidates for adjuvant therapy among those with early-stage NSCLC.

\section{CONCLUSIONS}

The present study identified poor or moderate histologic differentiation and elevated preoperative serum CEA as the 2 independent risk factors for recurrence in patients with stage IA NSCLC and 4 independent risk factors for recurrence in patients with stage I NSCLC (ie, poor or moderate histologic differentiation, elevated preoperative serum CEA, lymphovascular invasion, and tumor size $>2 \mathrm{~cm}$ ). When these 4 risk factors were combined, a high-risk recurrence group consisting of those patients with $>2$ risk factors was identified in patients with stage I NSCLC. These patients were considered potential candidates for adjuvant chemotherapy.

We gratefully present our study in memory of Dr Yung-Chie Lee, the late chief of our department, who provided guidance, encouragement, wisdom and thoughtful criticism throughout the studies.

\section{References}

1. Pisani P, Bray F, Parkin DM. Estimates of the world-wide prevalence of cancer for 25 sites in the adult population. Int J Cancer. 2002;97:72-81.

2. Hoffman PC, Mauer AM, Vokes EE. Lung cancer. Lancet. 2000;355:479-85.

3. Chang MY, Mentzer SJ, Colson YL, Linden PA, Jaklitsch MT, Lipsitz SR, et al. Factors predicting poor survival after resection of stage 1A non-small cell lung cancer. J Thorac Cardiovasc Surg. 2007;134:850-6.

4. Miller YE. Pathogenesis of lung cancer: 100 year report. Am J Respir Cell Mol Biol. 2005;33:216-23.

5. Maeda R, Yoshida J, Ishii G, Hishida T, Nishimura M, Nagai K. Risk factors for tumor recurrence in patients with early-stage (stage I and II) non-small cell lung cancer: patient selection criteria for adjuvant chemotherapy according to the seventh edition TNM classification. Chest. 2011;140:1494-502.

6. Lin J, Beer DG. Molecular predictors of prognosis in lung cancer. Ann Surg Oncol. 2012;19:669-76.

7. Sone S, Takashima S, Li F, Yang Z, Honda T, Maruyama Y, et al. Mass screening for lung cancer with mobile spiral computed tomography scanner. Lancet. 1998; 351:1242-5.

8. American Joint Committee on Cancer, Edge S, Byrd DR, Compton CC, Fritz AG, Greene FI, Trotti A III, eds. Lung. In: AJCC Cancer Staging Manual. 7th ed. New York: Springer; 2010:253-70.

9. Ichinose Y, Yano T, Asoh H, Yokoyama H, Yoshino I, Katsuda Y. Prognostic factors obtained by a pathologic examination in completely resected non-small-cell lung cancer: an analysis in each pathologic stage. J Thorac Cardiovasc Surg. 1995;110:601-5.

10. Maeda R, Yoshida J, Ishii G, Hishida T, Aokage K, Nishimura M, et al. Longterm survival and risk factors for recurrence in stage I non-small cell lung cancer patients with tumors up to $3 \mathrm{~cm}$ in maximum dimension. Chest. 2010;138: 357-62.

11. Miyoshi K, Moriyama S, Kunitomo T, Nawa S. Prognostic impact of intratumoral vessel invasion in completely resected pathologic stage I non-small cell lung cancer. J Thorac Cardiovasc Surg. 2009;137:429-34.

12. Sawabata N, Ohta M, Takeda S, Hirano H, Okumura Y, Asada H, et al. Serum carcinoembryonic antigen level in surgically resected clinical stage I patients with non-small cell lung cancer. Ann Thorac Surg. 2002;74:174-9.

13. Grunnet M, Sorensen JB. Carcinoembryonic antigen (CEA) as tumor marker in lung cancer. Lung Cancer. 2012;76:138-43.

14. Okada M, Nishio W, Sakamoto T, Uchino K, Yuki T, Nakagawa A, et al. Prognostic significance of perioperative serum carcinoembryonic antigen in nonsmall cell lung cancer: analysis of 1,000 consecutive resections for clinical stage I disease. Ann Thorac Surg. 2004;78:216-21.

15. Okada M, Nishio W, Sakamoto T, Uchino K, Yuki T, Nakagawa A, et al. Effect of histological type and smoking status on interpretation of serum 
carcinoembryonic antigen value in non-small cell lung carcinoma. Ann Thorac Surg. 2004;78:1009-10.

16. Koo HK, Jin SM, Lee CH, Lim HJ, Yim JJ, Kim YT, et al. Factors associated with recurrence in patients with curatively resected stage I-II lung cancer. Lung Cancer. 2011;73:222-9.

17. Travis WD, Brambilla E, Müller-Hermelink H, Harris CC, eds. Pathology and Genetics of Tumours of the Lung, Pleura, Thymus and Heart. Lyon: IARC Press; 2004:10-1.

18. Shen KR, Meyers BF, Larner JM, Jones DR. Special treatment issues in lung cancer: ACCP evidence-based clinical practice guidelines (2nd edition). Chest. 2007;132:290S-305S
19. Rice TW, Blackstone EH, Rusch VW. 7th Edition of the AJCC Cancer Staging Manual: esophagus and esophagogastric junction. Ann Surg Oncol. 2010;17: 1721-4.

20. Winton T, Livingston R, Johnson D, Rigas J, Johnston M, Butts C, et al. Vinorelbine plus cisplatin vs. observation in resected non-small-cell lung cancer N Engl J Med. 2005:352:2589-97.

21. Douillard JY, Rosell R, De Lena M, Carpagnano F, Ramlau R, GonzálesLarriba JL, et al. Adjuvant vinorelbine plus cisplatin versus observation in patients with completely resected stage IB-IIIA non-small-cell lung cancer (Adjuvant Navelbine International Trialist Association [ANITA]): a randomised controlled trial. Lancet Oncol. 2006;7:719-27.

Access to The Journal of Thoracic and Cardiovascular Surgery Online is reserved for print subscribers!

Full-text access to The Journal of Thoracic and Cardiovascular Surgery Online is available for all print subscribers. To activate your individual online subscription, please visit The Journal of Thoracic and Cardiovascular Surgery Online, point your browser to http://www.mosby.com/itcvs, follow the prompts to activate your online access, and follow the instructions. To activate your account, you will need your subscriber account number, which you can find on your mailing label (note: the number of digits in your subscriber account number varies from 6 to 10 ). See the example below in which the subscriber account number has been circled:

\section{Sample mailing label}

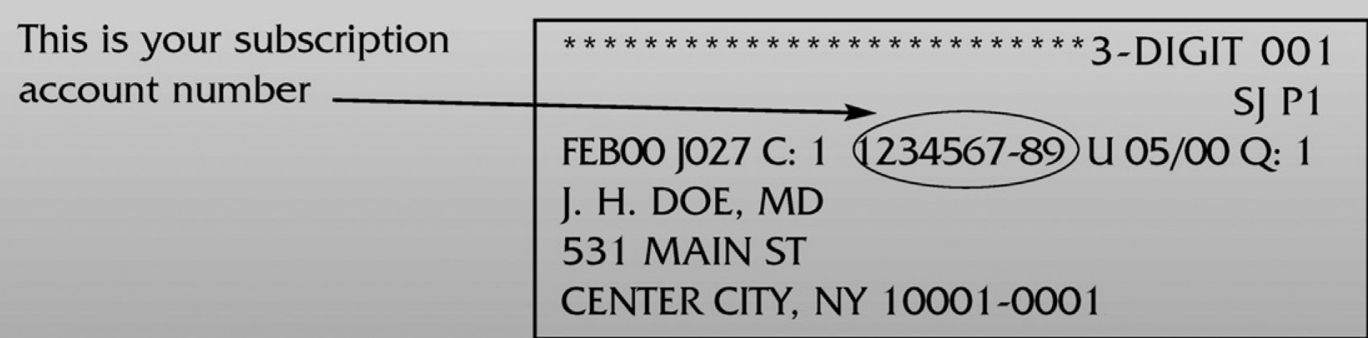

Personal subscriptions to The Journal of Thoracic and Cardiovascular Surgery Online are for individual use only and may not be transferred. Use of The Journal of Thoracic and Cardiovascular Surgery Online is subject to agreement to the terms and conditions as indicated online. 
TABLE E1. Recurrence sites of 112 patients with stage I distant recurrence

\begin{tabular}{lc}
\hline \multicolumn{1}{c}{ Recurrence site } & Patients* (n) \\
\hline Lung $\dagger$ & $68(60.7)$ \\
Bone & $31(27.7)$ \\
Brain & $17(15.2)$ \\
Pleural seeding and/or malignant pleural effusion & $14(12.5)$ \\
Liver & $9(8.0)$ \\
Chest wall, skin, soft tissue & $5(4.5)$ \\
Adrenal & $4(3.6)$ \\
Gastrointestinal tract & $1(0.9)$ \\
Intraperitoneal seeding & $1(0.9)$ \\
\hline Data in parentheses are percentages. *Of the 112 patients with distant recurrence, 31 \\
had $>1$ recurrence site at diagnosis. $\dagger$ Intrapulmonary metastasis was defined accord- \\
ing to the recommendations of the American College of Chest Physicians in 2007.
\end{tabular}


TABLE E2. Recurrence-free probability and clinicopathologic characteristics of patients with stage I (univariate analysis)

\begin{tabular}{|c|c|c|c|c|}
\hline \multirow[b]{2}{*}{ Characteristic } & \multirow[b]{2}{*}{ Patients (n) } & \multicolumn{2}{|c|}{ Recurrence-free probability (\%) } & \multirow[b]{2}{*}{$P$ value } \\
\hline & & 3 y $(95 \%$ CI $)$ & 5 y $(95 \%$ CI $)$ & \\
\hline Age $(y)$ & & & & $.002 *$ \\
\hline$\leq 65$ & 455 & $81.8(78.2-85.6)$ & $80.2(76.3-84.3)$ & \\
\hline$>65$ & 303 & $74.3(69.3-79.6)$ & $68.8(63.0-75.1)$ & \\
\hline Gender & & & & $.032 *$ \\
\hline Female & 404 & $80.8(76.9-85.0)$ & $79.6(75.5-83.9)$ & \\
\hline Male & 354 & $76.7(72.2-81.4)$ & $70.6(65.1-76.6)$ & \\
\hline Smoking & & & & $<.001 *$ \\
\hline No & 378 & $83.0(79.2-87.1)$ & $82.3(78.3-86.4)$ & \\
\hline Yes & 165 & $78.4(72.1-85.3)$ & $71.1(62.9-80.3)$ & \\
\hline NA & 215 & & & \\
\hline CEA & & & & $<.001 *$ \\
\hline Normal & 657 & $82.4(79.4-85.5)$ & $79.2(75.8-82.8)$ & \\
\hline Abnormal & 76 & $53.0(59.4-66.0)$ & $49.3(38.7-62.8)$ & \\
\hline NA & 25 & & & \\
\hline Other malignancy & & & & .208 \\
\hline No & 637 & $79.4(76.1-82.7)$ & $76.8(73.3-80.6)$ & \\
\hline Yes & 121 & $76.4(68.9-84.7)$ & $69.2(60.0-79.9)$ & \\
\hline Family history & & & & .093 \\
\hline No & 712 & $78.3(75.2-81.5)$ & $74.9(71.4-78.6)$ & \\
\hline Yes & 46 & $88.8(79.9-98.6)$ & $88.8(79.9-98.6)$ & \\
\hline Histologic type & & & & $<.001 *$ \\
\hline Adenocarcinoma & 541 & $77.7(74.1-81.5)$ & $74.4(70.3-78.6)$ & \\
\hline Bronchioloalveolar carcinoma & 93 & $96.7(93.1-100)$ & $96.7(93.1-100)$ & \\
\hline Squamous cell carcinoma & 83 & $64.9(55.0-76.7)$ & $58.2(47.3-71.7)$ & \\
\hline Other & 41 & $81.7(70.3-95.0)$ & $81.7(70.3-95.0)$ & \\
\hline Histologic differentiation & & & & $<.001 *$ \\
\hline Well & 306 & $91.6(88.4-94.9)$ & $90.2(86.5-94.0)$ & \\
\hline Moderately or poorly & 350 & $68.4(63.5-73.8)$ & $62.8(57.2-68.9)$ & \\
\hline NA & 102 & & & \\
\hline Surgical procedure & & & & .118 \\
\hline Wedge or segmentectomy & 114 & $85.9(79.4-92.8)$ & $82.1(73.1-92.3)$ & \\
\hline Lobectomy or bilobectomy & 644 & $77.8(74.6-81.2)$ & $74.7(71.1-78.5)$ & \\
\hline Approach & & & & $.012 *$ \\
\hline Thoracotomy & 109 & $69.7(61.5-79.1)$ & $67.3(58.8-77.1)$ & \\
\hline VATS & 649 & $80.3(77.1-83.6)$ & $76.9(73.2-80.7)$ & \\
\hline Tumor size $(\mathrm{cm})$ & & & & $<.001 *$ \\
\hline$\leq 2$ & 352 & $89.7(86.4-93.2)$ & $85.2(80.5-90.2)$ & \\
\hline $2 \sim 3$ & 214 & $73.0(67.0-79.5)$ & $69.0(62.5-76.2)$ & \\
\hline $3 \sim 5$ & 192 & $65.6(59.0-72.9)$ & $64.8(58.2-72.2)$ & \\
\hline Tumor site & & & & .241 \\
\hline LUL & 185 & $77.6(71.5-84.1)$ & $76.6(70.3-83.4)$ & \\
\hline LLL & 116 & $81.9(75.0-89.5)$ & $78.3(70.2-87.3)$ & \\
\hline RUL & 248 & $83.8(79.1-88.7)$ & $78.0(72.3-84.1)$ & \\
\hline RML & 69 & $68.5(57.4-81.6)$ & $65.4(53.6-79.7)$ & \\
\hline RLL & 140 & $74.0(66.7-82.1)$ & $74.0(66.7-82.1)$ & \\
\hline Visceral pleural invasion & & & & $<.001 *$ \\
\hline Negative & 635 & $81.8(78.7-85.0)$ & $78.7(75.3-82.4)$ & \\
\hline Positive & 123 & $63.9(55.6-73.4)$ & $59.8(50.6-70.6)$ & \\
\hline Lymphovascular invasion & & & & $<.001 *$ \\
\hline Negative & 656 & $82.0(78.9-85.1)$ & $80.1(76.8-83.5)$ & \\
\hline Positive & 102 & $59.0(49.8-70.0)$ & $46.6(35.9-60.5)$ & \\
\hline
\end{tabular}


TABLE E3. Recurrence-free probability and clinicopathologic characteristics of patients with stage IA

\begin{tabular}{|c|c|c|c|c|}
\hline \multirow[b]{2}{*}{ Characteristic } & \multirow[b]{2}{*}{ Patients (n) } & \multicolumn{2}{|c|}{$\begin{array}{l}\text { Recurrence-free } \\
\text { probability }(\%)\end{array}$} & \multirow[b]{2}{*}{$P$ value } \\
\hline & & $3 \mathbf{y}$ & $5 y$ & \\
\hline Age (y) & & & & $.006^{*}$ \\
\hline$\leq 65$ & 311 & 88.5 & 86.5 & \\
\hline$>65$ & 170 & 81.8 & 74.4 & \\
\hline Gender & & & & $.015^{*}$ \\
\hline Female & 273 & 88.8 & 86.9 & \\
\hline Male & 208 & 82.8 & 75.6 & \\
\hline Smoking & & & & $.030 *$ \\
\hline No & 255 & 88.9 & 87.8 & \\
\hline Yes & 93 & 84.5 & 75.2 & \\
\hline NA & 133 & & & \\
\hline CEA & & & & $<.001 *$ \\
\hline Normal & 435 & 88.6 & 84.8 & \\
\hline Abnormal & 32 & 60.1 & 55.1 & \\
\hline NA & 14 & & & \\
\hline Other malignancy & & & & .074 \\
\hline No & 400 & 86.9 & 84.4 & \\
\hline Yes & 81 & 82.7 & 70.9 & \\
\hline Family history & & & & .071 \\
\hline No & 448 & 85.5 & 81.4 & \\
\hline Yes & 33 & 97.0 & 97.0 & \\
\hline Histologic type & & & & $<.001 *$ \\
\hline Adenocarcinoma & 343 & 85.1 & 80.8 & \\
\hline $\begin{array}{l}\text { Bronchioloalveolar } \\
\text { carcinoma }\end{array}$ & 85 & 97.6 & 97.6 & \\
\hline Squamous cell carcinoma & 34 & 68.7 & 58.3 & \\
\hline Other & 19 & 85.9 & 85.9 & \\
\hline Histologic differentiation & & & & $<.001 *$ \\
\hline Well & 250 & 94.4 & 92.5 & \\
\hline Moderately or poorly & 168 & 75.9 & 68.1 & \\
\hline NA & 63 & & & \\
\hline Surgical procedure & & & & .999 \\
\hline Wedge or segmentectomy & 101 & 87.5 & 83.4 & \\
\hline Lobectomy or bilobectomy & 380 & 86.1 & 82.2 & \\
\hline Approach & & & & $.039 *$ \\
\hline Thoracotomy & 41 & 73.1 & 73.1 & \\
\hline VATS & 440 & 87.4 & 82.8 & \\
\hline Tumor size $(\mathrm{cm})$ & & & & $<.001 *$ \\
\hline$\leq 1$ & 135 & 94.7 & 92.2 & \\
\hline $1-2$ & 189 & 88.1 & 83.5 & \\
\hline $2-3$ & 157 & 76.6 & 72.6 & \\
\hline Tumor site & & & & .308 \\
\hline LUL & 115 & 83.8 & 83.8 & \\
\hline LLL & 73 & 89.5 & 83.3 & \\
\hline RUL & 168 & 90.7 & 84.2 & \\
\hline RML & 43 & 82.9 & 78.0 & \\
\hline RLL & 82 & 79.4 & 79.4 & \\
\hline Lymphovascular invasion & & & & $<.001 *$ \\
\hline Negative & 445 & 87.2 & 85.2 & \\
\hline Positive & 36 & 73.8 & 51.5 & \\
\hline
\end{tabular}

$N A$, Not available; $C E A$, carcinoembryonic antigen; VATS, video-assisted thoracoscopic surgery; $L U L$, left upper lobe; $L L L$, left lower lobe; $R U L$, right upper lobe; $R M L$, right middle lobe; $R L L$, right lower lobe. *Statistically significant. 